\title{
Do primary care physicians coordinate ambulatory care for chronic disease patients in Canada?
}

\author{
Alan Katz ${ }^{1 *}$, Patricia Martens ${ }^{2}$, Dan Chateau², Bodgan Bogdanovic ${ }^{3}$ and Ina Koseva ${ }^{3}$
}

\begin{abstract}
Background: Adults with chronic disease are the most frequent users of the primary healthcare system. In Manitoba, patients are allowed to seek ambulatory (outpatient) care from the provider of their choosing (primary care physician or specialist), with referrals to specialists preferred but not always required. Some patients receive their routine care from specialists. We conducted this study to determine the patterns by which adults with chronic disease access ambulatory care as a prelude to exploring the impact these patterns may have on the quality of care received.

Methods: Physician claims for all visits between 2007/8-2009/10 were extracted from the Data Repository at the Manitoba Centre for Health Policy. Patients included in the analysis made at least four ambulatory visits to a primary care physician or specialist within the study period, and met the definition criteria for at least one of six chronic diseases: diabetes mellitus; congestive heart failure; mood disorders; ischemic heart disease; total respiratory morbidity; and/or hypertension. Patients were "assigned" to the physician they visited most regularly. Physician visit patterns were assessed by dividing visits into nine visit types based on the type of physician patients visited (assigned primary care physician, other primary care physician, or specialist) and whether or not they received a referral.
\end{abstract}

Results: 347,606 patients with 7,662,411 physician visits were included in the analysis. Most visits were to the patients' assigned primary care physician. About $50 \%$ of the visits to specialists were by referral from the assigned primary care physician. However, 26-29\% of all visits to a primary care physician were not to the assigned primary care physician, and non-assigned physicians were more likely to refer patients to specialists than assigned primary care physicians.

Conclusion: The findings suggest that the current primary care system in Manitoba may not adequately support coordination of ambulatory care. Ambulatory visits to a primary care provider who is not the patient's regular provider may represent a lost opportunity for coordination and continuity of care, and may affect the quality of care patients receive. Primary care renewal initiatives in this province should address this challenge to service provision.

Keywords: Ambulatory care, Family physician, Primary care provider, Specialist, Continuity of care, Coordinated care

\section{Background}

The Canadian healthcare system is widely perceived to have a strong emphasis on primary care, which has been shown to be the foundation for a cost-effective healthcare system promoting better population health [1]. In an effort to bring healthcare spending under control, significant investment in primary care renewal has been

\footnotetext{
*Correspondence: Alan_Katz@cpe.umanitoba.ca

'Departments of Family Medicine and Community Health Sciences, College of Medicine, Faculty of Health Sciences, University of Manitoba, Manitoba Centre for Health Policy, 408-727 McDermot Ave, Winnipeg, Manitoba R3E 3P5, Canada

Full list of author information is available at the end of the article
}

made, including the development of salaried models for physician care and integration of inter-professional teams in primary care [2]. The aim of these initiatives is to create a highly functioning primary care system that will result in a healthier population and less use of expensive secondary and tertiary care. Over the last decade, almost all Canadian provinces, including Manitoba, have invested in primary care renewal $[3,4]$.

Patients suffering from chronic disease are frequent users of the primary healthcare system $[5,6]$ and are the most likely population to benefit from healthcare renewal initiatives, such as improvements in coordination 
of care. Coordination of care refers to the delivery of services by different care providers in a timely and complementary manner in order to achieve connected and cohesive patient care' [7], and is a core element of patient-centred primary care [8]. High quality wellcoordinated care is to a large extent dependent on continuity of care, an aspect of coordination described as a longitudinal and interpersonal relationship between the patient and the provider, whereby patients and physicians are cooperatively engaged in ongoing healthcare management [9]. Continuity is often explained in terms of three dimensions: 1) relational (the patient's experience of a continuous, caring relationship); 2) information (sharing of information between different health care providers); and 3) management (the physician aims to provide seamless, integrative healthcare service) $[10,11]$. This type of care is both a fundamental component of primary care and a significant contributor to good health outcomes [12-14]. Coordinated care for chronic disease involves input from a wide range of health professionals [15], and thus requires an informed healthcare team to ensure good communication among healthcare providers and patients and to facilitate optimal care [16]. A call to action from the Canadian Academy of Health Sciences recommends that the Canadian healthcare system provide all people with chronic disease with access to assigned clinicians or teams of clinicians responsible for providing their primary care and for coordinating care with acute, specialty, and community services throughout their life spans [17].

In Manitoba, ambulatory care (non-emergency, conditionspecific single visit or episodic care provided on an outpatient basis in support of primary care) is offered by primary care physicians, nurse practitioners and specialist physicians, and patients are free to seek ambulatory care from any provider of their choosing. But while primary care is the recommended route of access to advanced medical care (with a referral from a primary care physician usually required for access to a specialist [18]), Manitobans may also access specialist care via alternate routes. These routes include referral to a specialist by a primary care physician who is not the patient's regular provider, direct patient contact with a specialist without any referral, and provision of routine care from specialists.

Little is known about the patterns of routine ambulatory care Manitoban patients with chronic disease receive from their physicians. Whether accessing specialist care via the alternative routes described above or receiving care from a "non-assigned" primary care provider has consequences on the quality of care received, for example, by disrupting coordination and continuity of care, has not been established. Therefore, the objective of this study was to examine the patterns of primary physician and specialist use by adults with specific types of chronic disease in order to assess whether their care fits within the recommended patterns of coordinated care.

\section{Methods \\ Setting}

Manitoba is a central Canadian province with a population of about $1,250,500$ [19]. Just over $55 \%$ of the total population resides in the capital city of Winnipeg, and the rest live in smaller communities of 47,000 or fewer residents. The physician visit patterns of residents of Manitoba's second largest urban community (Brandon, pop 46,061) were similar to rural Manitobans. Therefore, the study compared Winnipeg to non-Winnipeg patterns when exploring the impact of geography on service use.

\section{Data sources and data period}

The study was conducted at the Manitoba Centre for Health Policy (MCHP) at the University of Manitoba. MCHP houses the Population Health Research Data Repository (herein referred to as the Repository). The Repository contains data derived from administrative claims collected by Manitoba Health, the Government of Manitoba department that administers the universal healthcare system within the province. These data provide comprehensive information of key interest to health planners, including person-level data such as birth and mortality, contacts with physicians and hospitals, pharmaceutical dispensing, and use of nursing homes, as well as 6-digit postal code data to derive area-level data such as region of residence. All data files in the Repository are 'de-identified', meaning that names and other identifying fields are not available, but unique (scrambled) identifiers are used to allow linkage across files and follow-up over time. Data in the Repository have been documented and validated extensively for this type of research [20]. Data used in this study are from the Population Health Research Data Repository (HIPC\# 2010/ 2011-35) housed at the Manitoba Centre for Health Policy, University of Manitoba and were derived from data provided by Manitoba Health and Province of Manitoba departments of Education, Family Services \& Labor, Entrepreneurship, Training \& Trade, the Healthy Child Manitoba Office, and the Winnipeg Regional Health Authority. Data from the fiscal years April $1^{\text {st }}, 2001$ to March $31^{\text {st }}, 2007$ were used to determine chronic disease prevalence, and data from April 1 $1^{\text {st }}, 2007$ to March $31^{\text {st }}, 2010$ were used for the physician visit patterns analyses.

\section{Study cohort}

Development of the study cohort is summarized in Figure 1. We identified all physician visits during the three-year study period by individuals who met the definition criteria for at least one of six chronic diseases: 


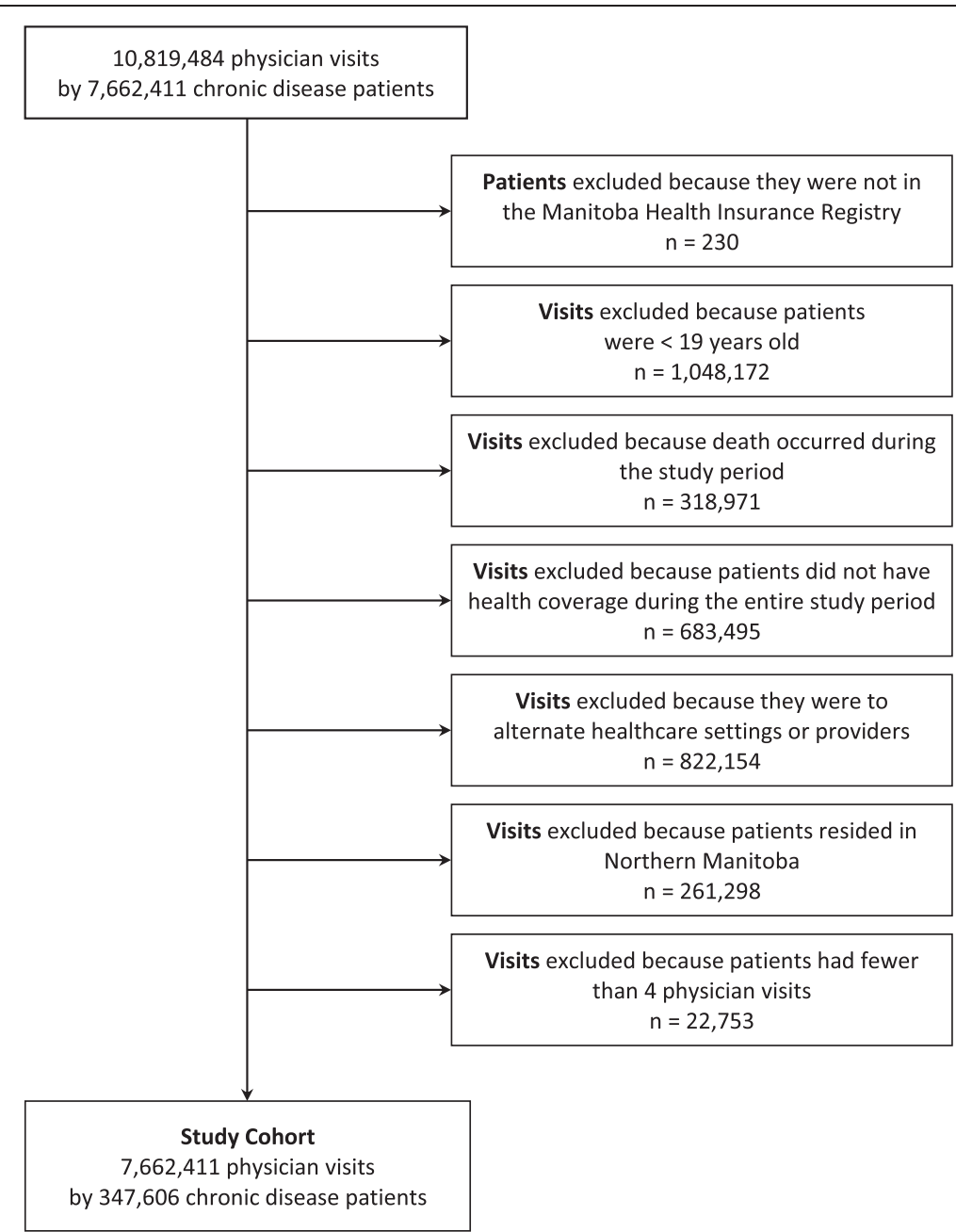

Figure 1 Criteria for developing the study cohort. Physician visit data from chronic disease patients was obtained from the Repository. Patients with one or more chronic disease(s) were included in the study if they met the following inclusion criteria: they were in the Manitoba Health Insurance Registry, were at least 19 years old, had lived in Manitoba during the entire study period, and had made at least 4 ambulatory visits to primary care physicians or specialists during the 3-year study period.

diabetes mellitus; congestive heart failure; mood disorders; ischemic heart disease; total respiratory morbidity; and/or hypertension (listed in Additional file 1). Individuals were included in the study if they were in the Manitoba Health Insurance Registry, had Manitoba health coverage throughout the study period, were 19 years of age or older at the start of the study period, and had made at least four ambulatory visits to a primary care physician or specialist (excluding radiologists, pathologists and anesthesiologists) within the study period. Individuals were excluded from the study if they were not living in Manitoba for the entire study period, and the year following the study period (to allow for follow-up). Patients whose records only included visits to emergency departments, inpatient hospitalizations, or doctors that were not active throughout the entire three-year study period, as well as those whose only visits were to specialists on referral from another physician, were excluded.

Residents of the three northern-most regional health authorities (RHAs; NOR-MAN, Burntwood and Churchill) were excluded from the study cohort, because our initial analyses indicated significant differences in the patterns of ambulatory care in these RHAs compared to the rest of the province. This is potentially due to the high percent of salaried physicians whose administrative claims are not always captured by the data, working in these areas [21]. Another contributing factor might be the lack of reporting of on-reserve First Nations nursing station visits to nurse practitioners. Our analyses also indicated a significant turnover of physicians practicing in these regions, making the 
application of the physician assignment algorithm (see below) difficult. In order to avoid introducing bias in our analyses, residents of the "North" (a total of 13,089 people) were excluded from this study as outliers. The final study cohort of Manitobans with chronic diseases included 347,606 individuals.

\section{Physician assignment algorithm}

The physician assignment algorithm (Figure 2) used to assign all individuals in the study cohort to a physician has been applied in numerous previous studies [21-25]. The algorithm is based on the frequency of ambulatory visits the patient has made to each physician. Only patients who had made at least four visits during the three-year study period were assigned to a physician. This study analyzed the choice of doctor patients made when seeking ambulatory care; therefore, prior to physician assignment, all visits that resulted from a referral from one physician to another (as indicated by a referral code in the medical claim) were excluded from the algorithm. We also excluded visits to emergency departments, visits to an inpatient setting, visits for maternity care, and visits to doctors that were not active during the entire study period.

\section{Ambulatory care visit patterns}

Visits to ambulatory care providers were divided into nine categories (Table 1). The first three categories included visits to a primary care physician. The next three categories included visits to a specialist without referral, and the last three categories included specialist visits made on referral. Referrals to specialists were determined from the associated billing codes that increase the value of the visit to the billing physician. We categorized all visits to a specialist within 6 months of a referral billing code as referred visits. The patterns of specialist visits with a referral were divided into categories based on who made the referral. The referring doctor could be a specialist, a primary care physician, or an inpatient/ emergency department physician. Although inpatient and emergency department visits were excluded from the main analyses, they were included when determining referrals since these doctors often provide referrals for future ambulatory specialist care.

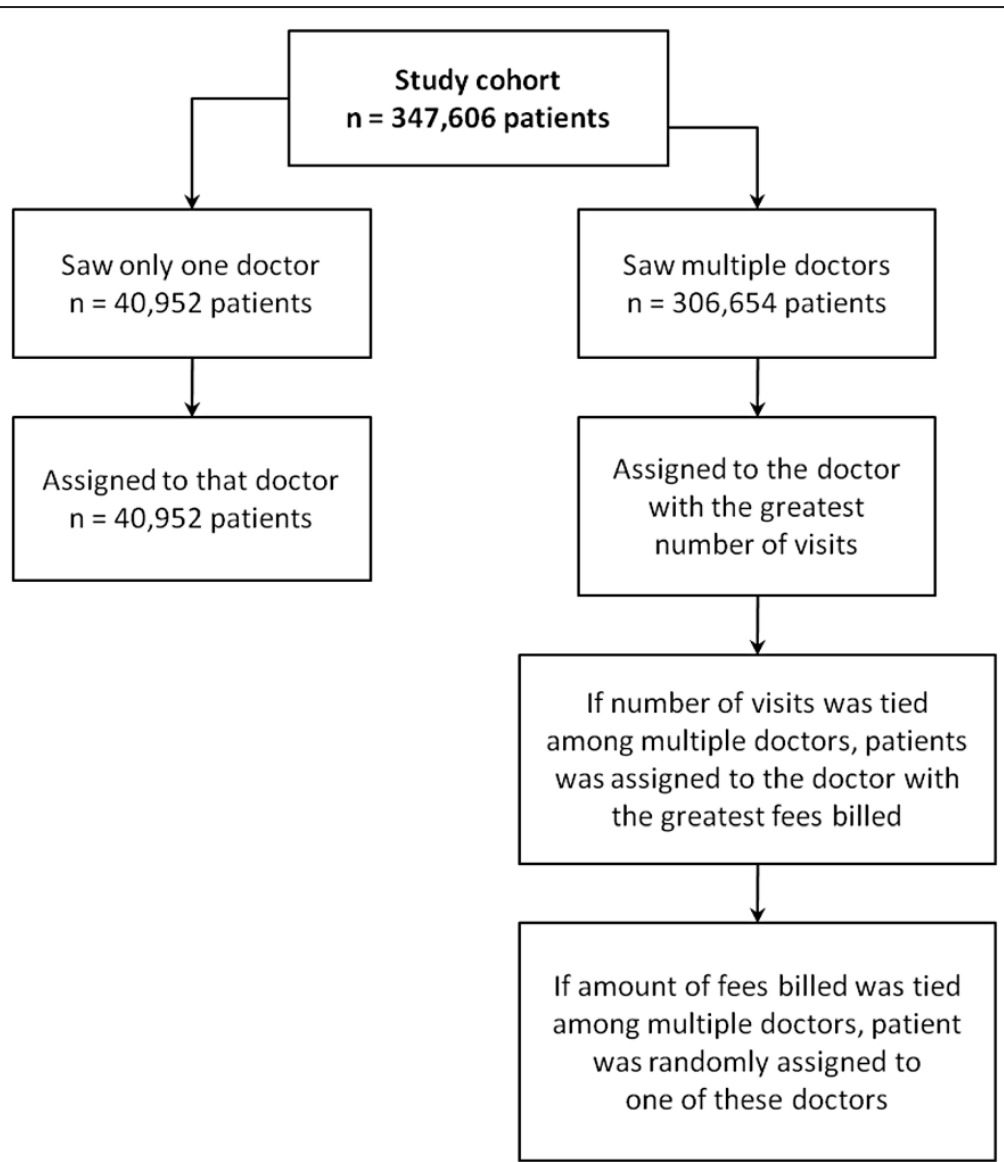

Figure 2 Physician assignment algorithm. Patients in the study cohort were assigned to a physician based on the frequency of their physician visits during the 3-year study period. 
Table 1 Ambulatory care visit patterns

\begin{tabular}{l} 
Visits to a primary care physician \\
\hline 1 Visits to the assigned PCP* \\
2 Visits to a PCP other than the assigned PCP \\
3 Visits to a PCP by patients assigned to a specialist \\
Visits to a Specialist without Referral \\
4 Visits to a specialist by patients with an assigned PCP \\
5 Visits to the assigned specialist \\
6 Visits to another (non-assigned) specialist \\
Visits to a Specialist with Referral \\
7 Visits with referral made by the patient's assigned PCP \\
8 Visits with referral made by another (non-assigned) PCP \\
9 Visits with referral made by another specialist \\
\hline
\end{tabular}

*PCP: primary care physician.

\section{Results}

Cohort characteristics

The study cohort included a total of 347,606 patients aged 19 and older. The distribution of the cohort by number of chronic diseases and area of residence (Winnipeg or non-Winnipeg) is presented in Table 2. The majority of study participants in Winnipeg and in the rest of the province had one chronic disease, with an inverse association between number of patients and number of diseases in both groups.

\section{Visit rates and patterns}

The total number of visits and visit rates over the threeyear study period are presented in Table 3. The average three-year visit rate per patient was similar for Winnipeg and non-Winnipeg residents. For Winnipeggers, $74 \%$ of all visits in the study period were to primary care physicians and the remainder were to specialists. In the nonWinnipeg group, $85 \%$ of all visits were to primary care physicians. Winnipeg residents visited specialist physicians nearly twice as often as non-Winnipeggers (5.86

Table 2 Distribution of chronic disease patients by location of residence and number of diseases

\begin{tabular}{|c|c|c|c|c|c|}
\hline \multirow{3}{*}{$\begin{array}{l}\text { Number } \\
\text { of chronic } \\
\text { diseases }\end{array}$} & \multicolumn{2}{|c|}{ Winnipeg } & \multicolumn{2}{|c|}{ Non-Winnipeg } & \multirow{3}{*}{$\begin{array}{c}\text { Total } \\
\text { number } \\
\text { of patients }\end{array}$} \\
\hline & $\#$ & $\%$ & $\#$ & $\%$ & \\
\hline & Patients & Patients & Patients & Patients & \\
\hline 1 & 133,405 & 62.74 & 79,229 & 37.26 & 212,634 \\
\hline 2 & 57,634 & 60.71 & 37,297 & 39.29 & 94,931 \\
\hline 3 & 18,720 & 60.62 & 12,161 & 39.38 & 30,881 \\
\hline 4 & 4,535 & 59.19 & 3,127 & 40.81 & 7,662 \\
\hline 5 & 794 & 57.20 & 594 & 42.80 & 1,388 \\
\hline 6 & 65 & 59.09 & 45 & 40.91 & 110 \\
\hline Total & 215,153 & 61.90 & 132,453 & 38.10 & 347,606 \\
\hline
\end{tabular}

Table 3 Ambulatory care visit rates of Manitoba chronic disease patients over 3 years by residence area

\begin{tabular}{lcc}
\hline & Winnipeg & Non-Winnipeg \\
\hline Number of Patients in Residence Area & 215,185 & 132,421 \\
Total Ambulatory Care Visits & $4,894,455$ & $2,767,956$ \\
Average Visits per Patient & 22.74 & 20.90 \\
Total Visits to Primary Care Physicians & $3,632,747$ & $2,350,554$ \\
Average Visits to Primary Care & 16.88 & 17.75 \\
Physicians per Patient & & \\
Total Visits to Specialists & $1,261,708$ & 417,402 \\
Average Visits to Specialists per Patient & 5.86 & 3.15 \\
\hline
\end{tabular}

visits per patient for Winnipeggers vs. 3.15 visits per patient for non-Winnipeggers over three years).

The visit patterns by patients whose assigned physician was a primary care physician are presented in Table 4. A visit to the assigned primary care physician was the most common route of accessing the ambulatory care system (52.6\% for Winnipeggers and 58.3\% for non-Winnipeg residents). In both groups, the second most common visit type was accessing a different (non-assigned) primary care physician. Specialist visits represented a greater percent of visits for Winnipeg residents than non-Winnipeg residents, and were equally divided between referred and non-referred visits regardless of geography. Among specialist visits, the most frequent type was to specialists assigned as the principal provider for that patient, representing $8.3 \%$ of visits for Winnipeg patients vs. $5.0 \%$ for non-Winnipeg residents. Among patients whose assigned physician was a specialist, only $1.4 \%$ and $0.4 \%$ of visits by Winnipeg and non-Winnipeg residents, respectively, were to a primary care physician.

Table 4 Ambulatory care visit and referral patterns of Manitoba chronic disease patients over 3 years by residence area: percent of total visits by patients with an assigned PCP*

\begin{tabular}{lll}
\hline Visit category & Winnipeg & Non-Winnipeg \\
\hline Visits to Assigned PCP & $\mathbf{5 2 . 5 5}$ & $\mathbf{5 8 . 2 9}$ \\
Visits to Another PCP & $\mathbf{1 7 . 3 1}$ & $\mathbf{2 3 . 1 0}$ \\
Visits to a Specialist by Referral & $\mathbf{1 3 . 3 4}$ & $\mathbf{7 . 9 9}$ \\
By Assigned PCP & 6.15 & 1.87 \\
By Another PCP & 4.81 & 4.19 \\
By Specialist & 2.38 & 1.93 \\
Visits to a Specialist without Referral & $\mathbf{1 3 . 4 0}$ & $\mathbf{7 . 8 2}$ \\
Assigned Physician is a PCP & 3.51 & 1.48 \\
Assigned Physician is the & 8.33 & 4.97 \\
Specialist visited & & \\
Assigned Physician is another Specialist & 1.56 & 1.37 \\
\hline
\end{tabular}

*PCP: primary care physician. Bold text indicates the percent of total visits; regular text is used to describe the referral patterns or assigned physician in each category. 


\section{Discussion}

\section{Main findings of the study}

This study examines the ambulatory visit pattern of Manitobans with specific types of chronic disease with the aim of determining whether their care fits within the recommended patterns, including continuity of care with one physician. The majority of visits were to a primary care physician, with just over half of all visits to the assigned primary care physician. However, $26.2 \%$ of all visits to a primary care physician in Winnipeg and $28.7 \%$ outside of Winnipeg over the three-year study period were not to the assigned primary care physician. These visits seem to represent a lost opportunity for wellcoordinated care. Patient access to specialist care without a referral was uncommon (13.7\% of visits for Winnipeg residents and $8.0 \%$ for non-Winnipeg residents). The highest proportion of specialist visits with referral was with a referral from a non-assigned primary care physician (4.8\% of all visits for Winnipeg and $4.2 \%$ for nonWinnipeg), particularly outside of Winnipeg where the rate of referral is more than twice as high from nonassigned physicians compared to assigned physicians.

\section{Is coordination of care supported by the current model of care in Manitoba?}

In Canada, all patients are free to choose their own primary care physician. Although direct access to specialists is possible, many provinces encourage access to specialist care via referral from a primary care physician by paying lower fees for non-referred consultations. In this way, primary care physicians act as "gatekeepers" to specialist care (i.e. secondary and tertiary care providers who do not generally have first contact with patients). The rationale for this recommended route of accessing ambulatory care is that it provides optimal continuity of care for the patient. Continuity and coordination of care are widely believed to be essential components of highquality patient care $[26,27]$ and have been shown to result in better patient health outcomes [28-30]. We have demonstrated that in Manitoba referrals for specialist consultation frequently originate from primary care physicians who are the not the patient's regular provider. These providers are less likely to be coordinating the patient's care, because they have not developed a continuous care relationship with the patient.

Visits of this nature may be generated through a number of circumstances. The non-assigned physician may work in the same clinic as the assigned provider and provide care while the assigned provider is away or not readily available. In this case, the non-assigned provider would likely have access to the patient's clinical record, ensuring continuity of information [11]. Alternatively the patient may have sought care from a different physician either due to the unavailability of the assigned physician or specifically to obtain the desired specialist referral that the assigned physician may not have felt appropriate or warranted. A non-assigned physician may be more likely to refer a patient for specialist care because of a lack of information about the patient's health history or previous care-seeking behaviours. Due to data limitations we were unable to determine which scenario is more or less responsible for the high proportion of the referrals that originated with non-assigned physicians.

Thirteen percent and $7.8 \%$ of visits to specialists by Winnipeg and non-Winnipeg patients, respectively, were made without any referral at all. Several studies have shown that geography is a factor in patient access to specialist care: urban centres in Canada have ten times as many specialists per capita as rural areas and rural residents are less likely to use specialist services than urban dwellers [31,32]. Higher socioeconomic status also predicts a higher frequency of specialist visits [33,34]. When patients visit multiple health care providers or access specialist care directly, communication among providers and between patients and physicians can be a challenge. Several other studies have emphasized the lack of effective communication between primary care physicians and specialists during the often cumbersome process of seeking consultation and integrating a new treatment plan $[35,36]$. This difficulty likely exacerbates the loss of coordinated care in situations where patients seek specialist care directly.

\section{Limitations of the data}

The limitations of this study are primarily related to the limitations in administrative claims data for physician visits, since the data used in this study were not developed specifically for research purposes. The study is based on physician claim data, which are submitted following visits to physicians remunerated on a fee-for-service basis. However, some physicians are paid through alternative mechanisms, in which case claims may not be submitted as reliably, and these visits would not have been included in the analysis. The number of visits to primary care physicians outside of Winnipeg is likely to be underestimated, as up to $40 \%$ of these physicians are paid via alternative funding arrangements [24]. Previous work has suggested that up to one-third of the visits to alternatively funded physicians may be missing from the claims data [21]. Claims are also missing from primary care physicians in Winnipeg because some (less than 10\%) of these are paid via alternative funding mechanisms and because services provided by nurse practitioners are not included during the years of study. We have not adjusted the results to address these gaps in the data but were forced to remove three northern regions with a high rate of alternatively funded primary care physicians, and thus we could not include the entire province's population. Studies have 
demonstrated that using the "majority-of-care" criterion for assigning physicians may overestimate the contribution of specialists and thus introduce bias [37]; however, these studies are based out of the U.S. where there is no gatekeeper function of primary care and should be interpreted with caution when examining a Canadian system. This study examines the patterns of physician access and referral in Manitoba, but is not intended to assess the quality of care ambulatory patients receive. It should also be noted that because the organization of the healthcare system differs among provinces and countries, this study has limited generalizability to other regions.

\section{Conclusion}

This population-based study demonstrates that the current primary care system in Manitoba does not fit the recommended patterns of coordination of ambulatory care. The reason for this discrepancy and the impact on the quality of care patients receive are as yet unknown. Other Canadian jurisdictions, including Ontario [3,38], Quebec [3,39] and Alberta [40], have moved to formal patient-provider attachment arrangements to support the fundamental principles of high quality primary care. Future research should explore the impact of those initiatives on referral rates and the origin of specialist referrals in those jurisdictions.

\section{Additional file}

Additional file 1: Definition Criteria for Chronic Conditions.

\section{Abbreviations}

MCHP: Manitoba Centre for Health Policy; RHA: Regional health authority.

\section{Competing interests}

The authors declare that they have no competing interests.

\section{Authors' contributions}

The study was conceptualized by AK, DC and PM. Analyses were performed by $\mathrm{BB}$ with the assistance of EK. The manuscript was a combined effort with input from all the authors. All authors read and approved the final manuscript.

\section{Acknowledgements}

The results and conclusions are those of the authors and no official endorsement by the Manitoba Centre for Health Policy, Manitoba Health, or other data providers is intended or should be inferred. The authors acknowledge Ms. Jennifer Enns, MSc, for assistance with drafting the manuscript.

\section{Funding}

This research was funded by the Department of Health of the Province of Manitoba.

\section{Author details}

1 Departments of Family Medicine and Community Health Sciences, College of Medicine, Faculty of Health Sciences, University of Manitoba, Manitoba Centre for Health Policy, 408-727 McDermot Ave, Winnipeg, Manitoba R3E 3P5, Canada. ${ }^{2}$ Department of Community Health Sciences, College of Medicine, Faculty of Health Sciences, University of Manitoba, Manitoba Centre for Health Policy, 408-727 McDermot Ave, Winnipeg, Manitoba R3E 3P5, Canada. ${ }^{3}$ Manitoba Centre for Health Policy, 408-727 McDermot Ave Winnipeg, Manitoba R3E 3P5, Canada.
Received: 4 June 2014 Accepted: 26 August 2014

Published: 30 August 2014

\section{References}

1. Freeman GK, Olesen F, Hjortdahl P: Continuity of care: an essential element of modern general practice? Fam Pract 2003, 20(6):623-627.

2. Gray DP, Evans P, Sweeney K, Lings P, Seamark D, Seamark C, Dixon M, Bradley N: Towards a theory of continuity of care. J R Soc Med 2003, 96(4):160-166

3. Stokes T, Tarrant C, Mainous AG 3rd, Schers H, Freeman G, Baker R: Continuity of care: is the personal doctor still important? A survey of general practitioners and family physicians in England and Wales, the United States, and The Netherlands. Ann Fam Med 2005, 3(4):353-359.

4. Starfield B: Primary care: an increasingly important contributor to effectiveness, equity, and efficiency of health services. SESPAS report 2012. Gac Sanit 2012, 26(Suppl 1):20-26.

5. van Soeren M, Hurlock-Chorostecki C, Pogue P, Sanders J: Primary healthcare renewal in Canada: a glass half empty? Healthc Pap 2008, 8(2):39-44 discussion 64-7.

6. Hutchison B, Levesque J, Strumpf E, Coyle N: Primary Health Care in Canada: Systems in Motion. Milbank Q 2011, 89(2):256-288.

7. Strumpf E, Levesque JF, Coyle N, Hutchison B, Barnes M, Wedel RJ: Innovative and diverse strategies toward primary health care reform: lessons learned from the Canadian experience. J Am Board Fam Med 2012, 25(Suppl 1):S27-S33.

8. Ostbye T, Yarnall KS, Krause KM, Pollak Kl, Gradison M, Michener IL: Is there time for management of patients with chronic diseases in primary care? Ann Fam Med 2005, 3(3):209-214.

9. Upshur RE, Tracy S: Chronicity and complexity: is what's good for the diseases always good for the patients? Can Fam Physician 2008, 54(12):1655-1658.

10. Haggerty JL, Pineault R, Beaulieu MD, Brunelle Y, Gauthier J, Goulet F, Rodrigue J: Practice features associated with patient-reported accessibility, continuity, and coordination of primary health care. Ann Fam Med 2008, 6(2):116-123.

11. Kringos D, Boerma W, Hutchinson A, van der Zee J, Groenewegen P: The breadth of primary care: a systematic literature review of its core dimensions. BMC Health Serv Res 2010, 10(1):65.

12. Saultz JW: Defining and measuring interpersonal continuity of care. Ann Fam Med 2003, 1(3):134-143.

13. Gulliford M, Naithani S, Morgan M: What is 'continuity of care'? J Health Serv Res Policy 2006, 11(4):248-250.

14. Haggerty JL, Reid RJ, Freeman GK, Starfield BH, Adair CE, McKendry R: Continuity of care: a multidisciplinary review. BMJ 2003, 327(7425):1219-1221.

15. Nolte E, McKee M: Caring for people with chronic conditions: A health system perspective. Berkshire, England: McGraw-Hill, Open University Press; 2008.

16. Law S, Flood C, Gagnon D, on behalf of the Listening for Direction III partners: National Consultation on Health Services and Policy Issues: Listening for Direction III. Ottawa, Canada: Canadian Health Services Research Foundation and Canadian Institutes of Health Research, Institute of Health Services and Policy Research; 2008.

17. Nasmith $L$, Ballem $P$, Baxter R, Bergman H, Colin-Thomé D, Herbert C, Keating N, Lessard R, Lyons R, McMurchy D, Ratner P, Rosenbaum P, Tamblyn R, Wagner E, Zimmerman B: Transforming care for Canadians with chronic health conditions: Put People First, Expect the Best, Manage for Results. Ottawa, Canada: Canadian Academy of Health Sciences; 2010.

18. Dunlop S, Coyte PC, Mclsaac W: Socio-economic status and the utilisation of physicians' services: results from the Canadian National Population Health Survey. Soc Sci Med 2000, 51(1):123-133.

19. Manitoba Health Population Report. [http://www.gov.mb.ca/health/population/]

20. Roos LL, Gupta S, Soodeen RA, Jebamani L: Data quality in an informationrich environment: Canada as an example. Can J Aging 2005, 24(Suppl 1):153-170.

21. Katz A, Soodeen RA, Bogdanovic B, De Coster C, Chateau D: Can the quality of care in family practice be measured using administrative data? Health Serv Res 2006, 41(6):2238-2254.

22. Frohlich N, Katz A, De Coster C, Dik N, Soodeen RA, Watson D, Bogdanovic B: Profiling primary care physician practice in Manitoba. Winnipeg, Canada: Manitoba Centre for Health Policy; 2006. 
23. Katz A, Bogdanovic B, Soodeen R: Physician integrated network baseline evaluation: linking electronic medical records and administrative data. Winnipeg, Canada: Manitoba Centre for Health Policy; 2010.

24. Katz A, De Coster C, Bogdanovic B, Soodeen R, Chateau D: Using administrative data to develop indicators of quality in family practice. Winnipeg, Canada: Manitoba Centre for Health Policy; 2004.

25. Martens P, Chateau D, Burland E, Prior H, Burchill C, Huq S, Romphf L, Sanguins J, Carter S, Bailly A: Profile of Metis health status and healthcare utilization in Manitoba: a population-based study. Winnipeg, Canada: Manitoba Centre for Health Policy; 2010.

26. Starfield B, Simborg D, Johns C, Horn S: Coordination of care and its relationship to continuity and medical records. Med Care 1977, 15(11):929-938

27. Editorial A: Continuity of care. J R Coll Gen Pract 1973, 23(136):749-750.

28. Weinberg DB, Gittell JH, Lusenhop RW, Kautz CM, Wright J: Beyond our walls: impact of patient and provider coordination across the continuum on outcomes for surgical patients. Health Serv Res 2007, 42(1 Pt 1):7-24

29. Christakis DA, Wright JA, Zimmerman FJ, Bassett AL, Connell FA: Continuity of care is associated with well-coordinated care. Ambul Pediatr 2003, 3(2):82-86.

30. Liss DT, Chubak J, Anderson ML, Saunders KW, Tuzzio L, Reid RJ: Patientreported care coordination: associations with primary care continuity and specialty care use. Ann Fam Med 2011, 9(4):323-329.

31. Pong RW, DesMeules M, Read Guernsey J, Manuel D, Kazanjian A, Wang F: Health Services Utilization in Rural Canada: Are There Distinct Rural Patterns? In Health in Rural Canada. Edited by Kulig JC, Williams AM. Vancouver: UBCPress; 2011:60-79.

32. Chan BT, Austin PC: Patient, physician, and community factors affecting referrals to specialists in Ontario, Canada: a population-based, multi-level modelling approach. Med Care 2003, 41(4):500-511.

33. Gill JM, Saldarriaga A, Mainous AG 3rd, Unger D: Does continuity between prenatal and well-child care improve childhood immunizations? Fam Med 2002, 34(4):274-280.

34. Frohlich N, Fransoo R, Roos N: Health service use in the Winnipeg Regional Health Authority: variations across areas in relation to health and socioeconomic status. Healthc Manage Forum 2002, Winter 2002 (Suppl):9-14.

35. Frost DW, Toubassi D, Detsky AS: Rethinking the consultation process: optimizing collaboration between primary care physicians and specialists. Can Fam Physician 2012, 58(8):825-828.

36. Durbin J, Barnsley J, Finlayson B, Jaakkimainen L, Lin E, Berta W, McMurray J: Quality of communication between primary health care and mental health care: an examination of referral and discharge letters. J Behav Health Serv Res 2012, 39(4):445-461.

37. Spiegel JS, Rubenstein LV, Scott B, Brook RH: Who is the primary physician? NEJM 1983, 308(20):1208-1212

38. Kralj B, Kantarevic J: Primary Care in Ontario: Reforms, investments and achievements. Toronto, Canada: Ontario Medical Association; 2012.

39. Breton M, Levesque JF, Pineault R, Hogg W: Primary Care Reform: Can Quebec's Family Medicine Group Model Benefit from the Experience of Ontario's Family Health Teams? Health Policy 2011, 7(2):e122-e135.

40. Alberta Medical Association: Discussion Paper: A Vision for Family Care Clinics. Edmonton, Canada: Alberta Medical Association; 2012.

doi:10.1186/1471-2296-15-148

Cite this article as: Katz et al:: Do primary care physicians coordinate ambulatory care for chronic disease patients in Canada? BMC Family Practice 2014 15:148.

\section{Submit your next manuscript to BioMed Central and take full advantage of:}

- Convenient online submission

- Thorough peer review

- No space constraints or color figure charges

- Immediate publication on acceptance

- Inclusion in PubMed, CAS, Scopus and Google Scholar

- Research which is freely available for redistribution

Submit your manuscript at www.biomedcentral.com/submit 